Research Paper

\title{
Interdependencies among Selected Pro-Inflammatory Markers of Endothelial Dysfunction, C-Peptide, Anti-Inflammatory Interleukin-10 and Glucose Metabolism Disturbance in Obese Women
}

\author{
Joanna Janowska1 ${ }^{\circledR}$, Jerzy Chudek¹, Magdalena Olszanecka-Glinianowicz², Elżbieta Semik-Grabarczyk ${ }^{3}$, \\ Barbara Zahorska-Markiewicz ${ }^{5}$ \\ 1. Department of Pathophysiology, Faculty of Medicine, Medical University of Silesia, Katowice, Poland \\ 2. Health Promotion and Obesity Management Unit, Department of Pathophysiology, Faculty of Medicine, Medical University of Silesia, Katowice, Poland \\ 3. Department of Internal, Autoimmune and Metabolic Diseases, Faculty of Medicine, Medical University of Silesia, Poland \\ 4. Faculty of Organization and Management, Silesian University of Technology, Gliwice, Poland \\ 5. Outpatient Clinic of Obesity and Metabolic Diseases "Waga”, Katowice, Poland
}

$\square$ Corresponding author: Joanna Janowska DSc. Email: jjanowska@sum.edu.pl. Department of Pathophysiology, Faculty of Medicine, Medical University of Silesia, 40-027 Katowice, street Medyków 18, Poland.

( ) Ivyspring International Publisher. Reproduction is permitted for personal, noncommercial use, provided that the article is in whole, unmodified, and properly cited. See http://ivyspring.com/terms for terms and conditions.

Received: 2015.10.12; Accepted: 2016.04.02; Published: 2016.06.25

\begin{abstract}
Background: Currently increasing importance is attributed to the inflammatory process as a crucial factor responsible for the progressive damage to vascular walls and progression of atherosclerosis in obese people. We have studied the relationship between clinical and biochemical parameters and C-peptide and anti-inflammatory IL-10, as well as selected markers of inflammation and endothelial dysfunction such as: CCL2, CRP, sICAM-1, sVCAM-1 and E-selectin in obese women with various degree of glucose metabolism disturbance.

Material and methods: The studied group consisted of 61 obese women, and 20 normal weight, healthy volunteers. Obese patients were spited in subgroups based on the degree of glucose metabolism disorder. Serum samples were analyzed using ELISA kits.

Results: Increased concentrations of sICAM-1, sVCAM-1, E-selectin, CCL2 and CRP were found in all obese groups compared to the normal weight subjects. In patients with Type 2 diabetes mellitus (T2DM) parameters characterizing the degree of obesity significantly positively correlated with levels of CRP and CCL2. Significant relationships were found between levels of glucose and sICAM- 1 and also E-selectin and HOMA-IR. C-peptide levels are positively associated with CCL2, E-selectin, triglycerides levels, and inversely with IL-10 levels in newly diagnosed T2DM group $(p<0.05)$. Concentrations of IL-10 correlated negatively with E-selectin, CCL2, C-peptide levels, and HOMA-IR in T2DM group $(\mathrm{p}<0.05)$.

Conclusion: Disturbed lipid and carbohydrate metabolism are manifested by enhanced inflammation and endothelial dysfunction in patients with simply obesity. These disturbances are associates with an increase of adhesion molecules. The results suggest the probable active participation of higher concentrations of C-peptide in the intensification of inflammatory and atherogenic processes in obese patients with type 2 diabetes. In patients with obesity and type 2 diabetes, altered serum concentrations of II- 10 seems to be dependent on the degree of insulin resistance and proinflammatory status.
\end{abstract}

Key words: Obesity, glucose metabolism disturbance, endothelial dysfunction, adhesion molecules, chemokine (C-C motif) ligand 2, C-peptide, interleukin-10. 


\section{Introduction}

Hyperglycemia significantly increases the risk of cardiovascular diseases development, and premature death in the population [1]. A characteristic feature of the atherosclerotic process in its course is a significant intensity. Both, obesity which is a major risk factor for the insulin resistance development and type 2 diabetes (T2DM), and the chronic hyperglycemia itself play an important role in its pathogenesis. Hyperglycemia contributes to glycosylation of proteins and lipids, increases the production of reactive oxygen species, stimulates the synthesis and secretion of pro-inflammatory cytokines and acute phase proteins in various tissues, promoting thus inflammation processes in the vascular wall $[2,3]$. It was found that postprandial glycemia in healthy people leads to a reduction of endothelium-dependent vasodilation through an increased lipid peroxidation and reduced bioavailability of nitric oxide [4]. Moreover, hyperglycemia stimulates the activation of endothelial cell apoptosis. Significant mechanisms associated with this process include oxidative stress, mitochondrial dysfunction and abnormal regulation of calcium metabolism [5-7]. Hyperglycemia is considered as an important reason of micro-and macrovascular complications in patients with diabetes, among which the most common are cardiovascular complications [8,9].

Dysfunctional endothelium is characterized by an increased expression of adhesion molecules responsible for the influx of leukocytes, their adhesion and migration to the subendothelial space. Important role in the formation of atherogenic changes both during the initiation period and atherosclerotic plaques destabilization is attributed to increased expression of intercellular adhesion molecules (ICAM-1), vascular cell adhesion molecules (VCAM-1) [10] and E-selectin [11]. As demonstrated in the epidemiological studies, an increase in the concentrations of their soluble forms in the circulation precedes the appearance of clinical signs and symptoms of atherosclerosis, and is a good predictor for future myocardial infarction [12].

Chemotactic cytokines, and especially proinflammatory chemokine (C-C motif) ligand 2 (CCL2), also known as monocyte chemotactic protein 1 (MCP-1), play a significant role in the process of atherosclerotic plaque formation. The last report presented by Arner et al. [13] demonstrated that micro RNAs, the regulator of inflammation in adipose tissue, stimulate the release of CCL2 from adipocytes and macrophages. CCL2 is responsible for the adhesion and migration of monocytes into the subendothelial space allowing their differentiation into macrophages and lipid-loaded foam cells [14]. In vitro studies demonstrated its proapoptotic activity on human umbilical vein endothelial cell (HUVEC) via a p53-dependent mitochondrial pathway [15]. Moreover, this chemokine affects angiogenesis by stimulation of VEGF-A gene expression [16]. A long-term increase in systemic concentrations of CCL2 is associated with macrophages infiltration in adipose tissue and systemic insulin resistance development in mice [17].

Available data indicate that interleukin 10 (IL-10) is the molecule of particular importance for the process of atherosclerosis related to the regulation of local inflammatory response. It inhibits the immune response initiated by cytokines released from activated monocytes/macrophages and lymphocytes, and reduces the synthesis of reactive oxygen [18]. Interleukin-10 inhibits the secretion of metalloproteinases, tissue factor and thrombin, and thus demonstrates a protective effect against plaque rupture and thrombus formation [19-21]. In addition, it exhibits an antiapoptotic activity, inter alia down-regulating the expression of Bcl2 modifying factor, activation of Stat3 phosphorylation and stimulation of ATP-binding cassette transporter A1 protein expression $[19,22,23]$. The important mechanisms through which this interleukin reduces the atherogenic process include inhibition of pro-inflammatory cytokines secretion by activated monocytes [24]. Except that, IL-10 facilitates the uptake of modified LDL by macrophages, as well as cholesterol excess transport from tissue macrophages [19]. It is believed that high levels of IL-10 are profitable prognostic factor [25], and better predictive marker of cardiovascular events occurrence in patients with acute coronary syndromes, than CRP and IL-18 [26].

C-reactive protein (CRP), an acute phase protein produced mainly in the liver under the influence of pro-inflammatory adipocytokines tumor necrosis factor alpha (TNF $\alpha$ ) and interleukin-6 (IL-6), is a recognized marker of inflammation. Its local source in the atherosclerotic plaque may also be macrophages. Moreover, CRP is directly involved in the formation and progression of atherogenic lesions. In macrophages it induces the secretion of tissue factor, secretion of inflammatory cytokines and reactive oxygen species (ROS), promotes monocyte chemotaxis and adhesion, and the formation of oxidized low-density lipoprotein (oxLDL) [27]. CRP deposition in the vascular wall is preceded by monocyte infiltration process, suggesting the 
participation of this protein in the early stages of atherosclerosis [28]. In addition, CRP contributes in the process of monocyte migration to the damaged endothelium [29]. In the smooth muscle cells, it increases inducible nitric oxide synthase (iNOS) production and activity of nuclear factor kappa-light-chain-enhancer of activated B cells (NF-KB) and mitogen-activated protein kinases (MAPK) pathways. It stimulates the expression of the receptor for angiotensin, contributes to an increase in the synthesis of free radicals, migration, proliferation of smooth muscle cells, activation of complement pathway, tissue factor expression and lipids uptake by macrophage [30]. C-reactive protein is considered to be an independent predictor of cardiovascular events [31] and chronic kidney disease in patients with type 2 diabetes [32].

Oversecretion of insulin, secondary to insulin resistance, is associated with the increased levels of C-peptide, a proinsulin cleavage product, regarded for a long time as biologically inactive. More recent data have revealed that C-peptide is the active molecule. As demonstrated it has an ability to bind to cell membranes via a specific G-protein-coupled receptor, which results in an activation of various signaling pathways such as kinases pathway associated with MAP and ERK $1 / 2$ proteins, protein kinase $C$, phosphoinositide 3-kinase, and stimulation of $\mathrm{Na}+, \mathrm{K}+$-ATPase [33,34]. Furthermore, C-peptide stimulates angiogenesis processes through an activation of extracellular signal-related kinase 1/2 and AKT phosphorylation, and NO synthesis [35]. The study on the development of late complications in type 1 diabetes highlighted its neuronal and nephroprotective activity. Furthermore, supplementation of C-peptide has been shown to improve microvascular complications in type 1 diabetes (T1DM) exclusively [36]. Recent studies on diabetic mice indicate its function protecting the retina from VEGF-induced microvascular leakage resulting, inter alia, from the reduction of ROS synthesis, stress fiber formation and vascular permeability [37]. Furthermore, C-peptide favors wound healing in diabetes by reducing inflammation and angiogenesis stimulation [35]. However, the relationship between C-peptide and atherogenesis is still a matter of controversy. It can stimulate the processes limiting inflammation and apoptosis in various cell types $[36,38,39]$. Unlike in the patients with type 2 diabetes, its elevated concentrations are supposed to intensify pro-inflammatory and atherogenic processes [40].

Explanation of the complex mechanisms involved in the atherogenic process, establishing of the link between obesity, type 2 diabetes and cardiovascular diseases, may have important prognostic value and allow in the future to develop more effective methods of prevention and treatment.

Keeping this perspective in mind, the purpose of the study was determination of the relationship between clinical and biochemical parameters and C-peptide and anti-inflammatory IL-10, as well as selected markers of inflammation and endothelial dysfunction such as: CCL2, CRP, sICAM-1, sVCAM-1 and E-selectin in obese women with various degree of glucose metabolism disturbance.

\section{Material and methods}

The studied group consisted of 61 women with simple obesity (BMI $>30 \mathrm{~kg} / \mathrm{m}^{2}$ ) referred to the Outpatient Clinic of Obesity and Metabolic Diseases and 20 lean, healthy volunteers with no family history of diabetes, who have been classified into one of the basic subgroups. The characteristics of the study subgroups are presented in Table 1 . The basis of creating the individual subgroups of obese patients was the degree of carbohydrate metabolism disorders. They included patients with newly diagnosed (untreated) T2DM, obese patients with impaired fasting glucose (IFG) and obese normoglycaemic (NFG) patients. Diagnostic criteria for diabetes were according to American Diabetes Association (ADA) [41]. In all the patients the following were excluded: acute infections, autoimmune diseases, cancers, hormonal disturbances, use of hormone replacement therapy, a reduction or increase in body weight of more than $5 \mathrm{~kg}$ in the year preceding the study, surgery performed during the six months period preceding the study, use of any drugs, alcohol consumption of more than 2 drinks per week, and smoking. Patients treated type 2 diabetes, secondary hypertension, and obesity were excluded. All the patients were fully informed of the nature and purpose of the study and they gave their written informed consent. The study complies with the Declaration of Helsinki. The study was approved by the Bioethics Committee of the Medical University of Silesia.

The clinical evaluation of patients included the measurement of height, body mass, waist circumference, body composition measured by bioelectrical impedance analysis (Bodystat 1500 apparatus), blood pressure (BP), routine laboratory tests and additionally blood sampling for assessment of sICAM-1, sVCAM-1, E-selectin, CCL2, CRP, IL-10, insulin and C-peptide serum levels. Blood samples were collected between 8.30 a.m.-10.00 a.m. from an antecubital vein into appropriate Vacutainer tubes in the amount of 10 milliliters $(\mathrm{mL})$, at least 12 hours after the last meal. After centrifugation, serum 
samples were distributed into plastic tubes and stored in a low temperature freezer $\left(-80^{\circ} \mathrm{C}\right)$ until determinations were made. Body mass index (BMI) was calculated according standard formula: $\mathrm{BMI}=$ mass $(\mathrm{kg}) /(\text { height }(\mathrm{m}))^{2}$. HOMA-IR (homeostasis model assessment of insulin resistance index) was calculated using the following equation:

HOMA-IR $(\mathrm{mmol} / \mathrm{L} \times \mu \mathrm{U} / \mathrm{ml})=$ fasting glucose $(\mathrm{mmol} / \mathrm{L}) \times$ fasting insulin $(\mu \mathrm{U} / \mathrm{ml}) / 22.5$

The fasting blood glucose, total cholesterol, HDL-cholesterol (HDLC) and triglycerides levels (TG) were determined by the standard laboratory techniques by using commercially available test kits (Point Scientific Inc.Michigan, USA). LDL-cholesterol (LDLC) was calculated using the Friedewald formula: LDLC $=$ TC - HDLC $-T G / 5$. Fasting insulin and fasting C-peptide levels were measured with commercial radioimmunoassay (RIA) kits (Diagnostic Products Corporation, Los Angeles, USA) with a lower sensitivity limit of $1.2 \mu \mathrm{IU} / \mathrm{ml} ; 0.318 \mathrm{ng} / \mathrm{mL}$ and intra-assay and inter-assay coefficients of variations of $5.2 \% ; 3.57 \%$ and $5.8 \%$; $5.59 \%$, respectively. Determinations of sICAM-1, sVCAM-1, E-selectin and CCL2 were made via enzyme immunoassay method using enzyme immunoassay kits (Diaclone SAS, Besancon Cedex, France), following the instructions enclosed by the manufacturer. The detection limit and intra- and interassay variations of the biomarkers were $0.1 \mathrm{ng} / \mathrm{ml}, \quad 2.8 \%$ and $8.2 \%$ for sICAM-1; $0.6 \mathrm{ng} / \mathrm{ml}, 2.3 \%$ and $5.9 \%$ for sVCAM-1; $0.5 \mathrm{ng} . \mathrm{ml}$, $4.2 \%$ and $6.4 \%$ for E-selectin; $2.3 \mathrm{pg} / \mathrm{ml}, 4.7 \%$ and $8.7 \%$ for CCL2, respectively. Plasma IL-10 and CRP concentration were measured with a human high-sensitivity immunoassays (Quantikine HS; R\&D Systems, Minneapolis, USA; Immunodiagnostic AG, Bensheim Germany, respectively) with the detection limit of the method and intra- and interassay variations: $0.5 \mathrm{pg} / \mathrm{ml}, 9.6 \% 15.7 \%$ (IL-10) and 0.01 $\mathrm{ng} / \mathrm{ml} 5.5 \%$ and $11.6 \%$ (CRP), respectively.

\section{Statistical analysis}

Data were presented as the means \pm SD. Distributions of the studied variables were examined using the Shapiro-Wilk, $\mathrm{Chi}^{2}$ or Kolmogorov-Smirnov tests. Comparison of variables with a normal distribution between groups Student's t-test was used (homogeneity of variance was determined as first using Fisher-Snedecor and Levene test). For variables with distribution other than normal, the Mann-Whitney $U$ test was used. For non-homogeneous variance of the compared groups with normal distribution, the Cochran-Cox $C$ test was used. A comparative analysis of three independent non-normally distributed groups was performed using the Kruskal-Wallis ANOVA test, whereas for heterogeneity of variance of the variables with a normal distribution tests were performed with independent variance estimation. Correlation coefficients were calculated according to Pearson and Spearman', as appropriate. Multivariate analysis was performed by stepwise multiple regression analysis using the research parameters (sICAM-1, sVCAM-1, E-selectin, CLL2, CRP, anti-inflammatory IL-10 and C-peptide) as the dependent variable and clinical and biochemical features as predictors in whole obese group of patients. A $p$ value $<0.05$ was considered statistically significant. All statistical calculations were performed using STATISTICA 10.0 PL software (StatSoft Polska, Krakow, Poland).

\section{Results}

\section{The characteristic of study subjects (Table 1)}

Analyzed clinical and biochemical parameters in subgroups of women with impaired glucose metabolism were significantly higher compared with the control group. Significant differences in the normal fasting glucose women compared to the control group were found only for body mass, BMI, fat mass percentage and waist circumference. The systolic and diastolic blood pressure did not differ significantly between NFG and control group. The comparison of biochemical parameter concentrations showed statistically significant differences between the T2DM, IFG subgroups and the control group, and between the T2DM and NFG subgroups (except levels of total cholesterol). In contrast, no significant differences were observed between the NFG subgroup and the control group. In the T2DM subgroup the lowest HDL-cholesterol levels and the highest levels of glucose were observed as compared to the other subgroups of obese. In addition, the concentrations of triglycerides, insulin, and HOMA-IR were significantly higher in the IFG subgroup compared to the NFG subgroup. Significantly higher C-peptide levels were found in the group with T2DM compared with the control group.

\section{Serum levels of pro-inflammatory markers and IL-10 (Table 2)}

The mean sICAM-1, sVCAM-1 and E-selectin serum levels in the studied subgroups of obese patients were significantly higher than the values obtained in the control group. The highest their values were observed in T2DM patients and they were about twice as high as those in the control group. In contrast, mean concentrations of these molecules in the IFG and NFG subgroups were similar. CCL2 and CRP 
concentrations in the studied subgroups of obese were similar, but significantly higher than obtained in the control group. IL-10 levels in the obese study subgroups were higher than the values obtained in the control group, but only in the T2DM and IFG subgroups the values were significantly increased.

\section{Significant correlations in the studied subgroups of obese women (Table 3)}

The serum levels of sICAM-1 in the T2DM subgroup were proportional to glucose $(\mathrm{p}<0.05)$ and E-selectin $(p<0.05)$ levels, and inversely related to HDL-cholesterol levels $(p<0.05)$. The concentrations of sVCAM-1 in the T2DM subgroup correlated significantly with triglyceride levels $(\mathrm{p}<0.05)$. In addition, in this subgroup there was a significant, positive correlation between E-selectin and HOMA-IR values $(p<0.05)$ and significant negative correlation with HDL-cholesterol levels ( $p<0.05)$. The CCL2 concentrations correlated with the BMI values in all subgroups of obese patients ( $p<0.05)$. IL-10 levels correlated significantly negatively in the subgroup of T2DM patients with concentrations of E-selectin, CCL2 ( $p<0.05)$, and of C-peptide ( $p<0.05)$, and values of HOMA-IR $(p<0.05)$. In patients with type 2 diabetes and IFG, parameters characterizing the degree of obesity significantly, positively correlated with the levels of CRP (T2DM: BMI, body mass, fat mass, waist circumference; IFG: BMI, body mass, fat mass; $p<0.05)$. While the positive correlations in the NFG group were seen only between fat mass and CRP levels ( $p<0.05)$. Moreover, CRP concentrations in T2DM subgroup correlated significantly with E-selectin levels $(p<0.05)$. In addition to the above-mentioned C-peptide concentrations in the T2DM subgroup correlated positively with the concentrations of triglycerides and CCL2 and E-selectin $(p<0.05)$.

\section{Multivariate stepwise regression analysis in whole study group of obese women (Table 4)}

Multivariate stepwise analysis showed that HOMA-IR was significantly associated with sICAM-1, E-selectin and C-peptide levels, while HDL-cholesterol had the strongest inverse relation with E-selectin and C-peptide levels in whole obese group. Additionally, in this analysis a body mass index was significant independent predictor for CRP levels, and fasting glucose for sICAM-1 levels.

Table 1. Characteristics of the study population.

\begin{tabular}{|c|c|c|c|c|}
\hline & $\begin{array}{l}\text { T2DM group } \\
(\mathrm{n}=15)\end{array}$ & $\begin{array}{l}\text { IFG group } \\
(\mathrm{n}=22)\end{array}$ & $\begin{array}{l}\text { NFG group } \\
(\mathrm{n}=24)\end{array}$ & $\begin{array}{c}\text { Control } \\
(n=20)\end{array}$ \\
\hline Age (years) & $48.1 \pm 6.5$ & $51.5 \pm 4.9$ & $48.1 \pm 5.9$ & $45.5 \pm 7.1$ \\
\hline Body mass (kg) & $103.3 \pm 13.9^{* *} \neq$ & $101.4 \pm 18.2^{* *}$ & $91.8 \pm 14.1^{* *}$ & $59.9 \pm 7 . .4$ \\
\hline BMI $\left(\mathrm{kg} / \mathrm{m}^{2}\right)$ & $39.8 \pm 4.8^{\star *}$ & $38.3 \pm 6.4^{\star *}$ & $35.1 \pm 5.1^{\star *}$ & $22.1 \pm 2.8$ \\
\hline Fat mass (\%) & $51.8 \pm 5.7^{\star *} \neq$ & $51.1 \pm 5.6^{* *} \neq$ & $46.7 \pm 7.3^{* *}$ & $28.5 \pm 8.8$ \\
\hline Waist circumference $(\mathrm{cm})$ & $108.2 \pm 7.9^{* *}$ & $110.3 \pm 12.4^{* *}$ & $102.9 \pm 12.9^{* *}$ & $74.1 \pm 6.2$ \\
\hline Systolic BP (mmHg)] & $142.7 \pm 22.5^{* *}$ & $143.6 \pm 13.1^{* *}$ & $114.5 \pm 14.5$ & $104.3 \pm 8.7$ \\
\hline Diastolic BP (mmHg) & $87.1 \pm 12.6^{* *}$ & $86.0 \pm 8.9^{* *}$ & $74.8 \pm 10.2$ & $68.6 \pm 6.1$ \\
\hline Total cholesterol (mg/dL) & $261.4 \pm 66.1^{* *}$ & $239.6 \pm 40.9^{* *}$ & $216.3 \pm 37.9$ & $187.9 \pm 20.1$ \\
\hline $\operatorname{HDLC}(\mathrm{mg} / \mathrm{dL})$ & $41.4 \pm 10.1^{*} \#-$ & $53.0 \pm 14.6^{* *}$ & $53.5 \pm 16.1$ & $62.1 \pm 12.1$ \\
\hline LDLC (mg/dL) & $198.7 \pm 68.4 *-$ & $151.5 \pm 41.3^{* *}$ & $141.1 \pm 40.1$ & $129.8 \pm 36.9$ \\
\hline Triglycerides (mg/dL) & $155.1 \pm 69.9^{* *} \neq$ & $154.5 \pm 100.2^{* *} \neq$ & $110.5 \pm 31.8$ & $79.0 \pm 26.2$ \\
\hline Fasting glucose (mg/dL) & $138.3 \pm 23^{* *} \# \# \neq$ & $102.4 \pm 11.4$ * & $91.7 \pm 6.3$ & $86.4 \pm 10.2$ \\
\hline Fasting insulin $(\mu \mathrm{IU} / \mathrm{mL})$ & $21.2 \pm 14.9^{* *} \neq$ & $16.2 \pm 5.8^{* *} \neq$ & $7.1 \pm 3.1$ & $6.3 \pm 3.1$ \\
\hline HOMA-IR & $6.1 \pm 5.7^{* * *} \neq$ & $4.1 \pm 1.5^{* *} \neq$ & $1.6 \pm 0.7$ & $1.4 \pm 0.6$ \\
\hline C-peptide (nmol/L) & $1.52 \pm 0.64^{*}$ & $1.10 \pm 0.47$ & $0.86 \pm 0.32$ & $0.83 \pm 0.4$ \\
\hline
\end{tabular}

Data are presented as mean \pm SD.

${ }^{*} \mathrm{p}<0.05 ;{ }^{* *} \mathrm{p}<0.001$ vs control; \# $\mathrm{p}<0.05$, \#\# $\mathrm{p}<0.001$ vs IFG; $\uparrow \mathrm{p}<0.05$, $\mathrm{p}<0.001$ vs NFG

Table 2. Serum levels of pro-inflammatory markers and interleukin-10

\begin{tabular}{|c|c|c|c|c|}
\hline & $\begin{array}{l}\text { T2DM group } \\
(\mathrm{n}=15)\end{array}$ & $\begin{array}{l}\text { IFG group } \\
(\mathrm{n}=22)\end{array}$ & $\begin{array}{l}\text { NFG group } \\
(\mathrm{n}=24)\end{array}$ & $\begin{array}{l}\text { Control } \\
(\mathrm{n}=20)\end{array}$ \\
\hline sICAM-1(ng/mL) & $684 \pm 63$ ** \# $\neq$ & $426 \pm 61$ * & $401 \pm 77^{*}$ & $356 \pm 80$ \\
\hline sVCAM-1(ng/mL) & $1612 \pm 434$ ** \# & $873 \pm 158$ ** & $838 \pm 156^{* *}$ & $539 \pm 112$ \\
\hline E-selectin(ng/mL) & $106.7 \pm 23.2^{*} \# \neq$ & $76.1 \pm 25.4^{*}$ & $75.3 \pm 26.4^{*}$ & $52.3 \pm 17.3$ \\
\hline CCL2 (pg/mL) & $289 \pm 112$ * & $242 \pm 105^{*}$ & $211 \pm 96$ * & $125 \pm 79$ \\
\hline CRP ( mg/L) & $5.6 \pm 3.18^{* *}$ & $5.03 \pm 3.9^{* *}$ & $4.3 \pm 3.1^{* *}$ & $1.06 \pm 0,78$ \\
\hline IL-10 (pg/mL) & $7.9 \pm 3.5^{*}$ & $6.4 \pm 2.1^{*}$ & $4.9 \pm 2.4$ & $3.4 \pm 1.4$ \\
\hline
\end{tabular}

Data are presented as mean $\pm \mathrm{SD}$

${ }^{*} \mathrm{p}<0.05 ;{ }^{* *} \mathrm{p}<0.001$ vs control; \# $\mathrm{p}<0.05, \# \# \mathrm{p}<0.001$ vs IFG; $\uparrow \mathrm{p}<0.05, \neq \mathrm{p}<0.001$ vs NFG 
Table 3. Significant correlations in the studied subgroups of obese women

\begin{tabular}{|c|c|c|c|c|c|c|}
\hline & $\begin{array}{l}\mathrm{T} 2 \mathrm{DM} \\
\text { group }\end{array}$ & $\begin{array}{l}\text { Correlation } \\
\text { Coefficients } \\
p<0.05\end{array}$ & $\begin{array}{l}\text { IFG } \\
\text { group }\end{array}$ & $\begin{array}{l}\text { Correlation } \\
\text { Coefficients } \\
p<0.05\end{array}$ & $\begin{array}{l}\text { NFG } \\
\text { group }\end{array}$ & $\begin{array}{l}\text { Correlation } \\
\text { Coefficients } \\
p<0.05\end{array}$ \\
\hline \multirow[t]{3}{*}{ sICAM-1 } & Glucose & 0.63 & - & - & - & - \\
\hline & E-selectin & 0.47 & - & - & - & - \\
\hline & HDLC & -0.57 & - & - & - & - \\
\hline sVCAM-1 & Triglycerides & 0.43 & - & - & - & - \\
\hline \multirow[t]{5}{*}{ E-selectin } & HOMA-IR & 0.33 & - & - & - & - \\
\hline & HDLC & -0.43 & - & - & - & - \\
\hline & C-peptide & 0.36 & - & - & - & - \\
\hline & IL-10 & -0.48 & - & - & - & - \\
\hline & CRP & 0.35 & - & - & - & - \\
\hline \multirow[t]{3}{*}{ CCL2 } & BMI & 0.41 & BMI & 0.31 & BMI & 0.26 \\
\hline & C-peptide & 0.35 & - & - & - & - \\
\hline & IL-10 & -0.27 & - & - & - & - \\
\hline \multirow[t]{4}{*}{ IL-10 } & E-selectin & -0.48 & - & - & - & - \\
\hline & CCL2 & -0.27 & - & - & - & - \\
\hline & HOMA-IR & -0.57 & - & - & - & - \\
\hline & C-peptide & -0.66 & - & - & - & - \\
\hline \multirow[t]{8}{*}{ CRP } & BMI & 0.52 & BMI & 0.29 & - & - \\
\hline & Body mass & 0.57 & Body & 0.32 & - & - \\
\hline & Fat mass & 0.45 & mass & 0.31 & Fat & 0.53 \\
\hline & Waist & & Fat & & mass & \\
\hline & circumference & 0.43 & mass & - & - & - \\
\hline & E-selectin & 0.35 & & - & - & - \\
\hline & & & - & & & \\
\hline & & & - & & & \\
\hline \multirow[t]{4}{*}{ C-peptide } & Triglycerides & 0.32 & - & - & - & - \\
\hline & E-selectin & 0.36 & - & - & - & - \\
\hline & CCL2 & 0.35 & - & - & - & - \\
\hline & IL-10 & -0.66 & - & - & - & - \\
\hline
\end{tabular}

Table 4. Multivariate stepwise regression analysis in whole study group of obese women

\begin{tabular}{|c|c|c|c|c|c|}
\hline $\begin{array}{l}\text { Dependent } \\
\text { variables }\end{array}$ & $\begin{array}{l}\text { Independent } \\
\text { variables }\end{array}$ & $\begin{array}{l}\text { Coefficient } \\
\text { Beta }\end{array}$ & $\mathrm{t}$ & $\begin{array}{l}\text { Statistical } \\
\text { significance }\end{array}$ & $\begin{array}{l}\text { Adjusted } \\
\mathrm{R}^{2}\end{array}$ \\
\hline CRP & BMI & 0,52 & 3.32 & 0.02 & 0.142 \\
\hline \multirow[t]{2}{*}{ sICAM-1 } & Glucose & 0.42 & 4.32 & $<0.001$ & 0.672 \\
\hline & HOMA-IR & 0.22 & 2.36 & 0.023 & \\
\hline \multirow[t]{2}{*}{ E-selectin } & HDLC & -0.39 & 3.78 & $<0.001$ & 0.170 \\
\hline & HOMA-IR & 0.43 & 3.4 & 0.001 & \\
\hline \multirow[t]{2}{*}{ C-peptide } & HDLC & -0.23 & 2.09 & $<0.041$ & 0.461 \\
\hline & HOMA-IR & 0.60 & 5.18 & $<0.001$ & \\
\hline
\end{tabular}

Only significant regressions are indicated.

\section{Discussion}

Metabolic disorders accompanying an excess of adipose tissue, in particular visceral one, through various mechanisms promote the activation of endothelial cells, increase the synthesis of reactive oxygen species, endoplasmic reticulum stress and therefore are responsible for the activation of inflammatory and fibroproliferative process in the vascular wall. Among many factors affecting endothelium in obese patients with T2DM, hyperglycemia is the most significant one. The immuno-inflammatory response is particularly important for the initiation as well as the progression of atherosclerosis.

As expected, the concentrations of soluble forms of adhesion molecules in all groups of obese women were significantly higher than these achieved in the lean control, but the highest ones were observed in the type 2 diabetes mellitus group. In patients with impaired fasting glucose their concentrations reach values higher than in the NFG subgroup, but the increase was not statistically significant. The positive correlation between the concentrations of glucose and sICAM-1 was noted only in T2DM group. This is consistent with the observations of Ziccardi et al. [42] who emphasize the role of high glucose levels in an intensification of adhesion molecules expression. Additionally, a positive correlation was observed between HOMA-IR and the concentrations of E-selectin, in T2DM subgroup. This correlation is especially significant, since E-selectin synthesized de novo by the endothelium activating factors, is a molecule expressed only by endothelial cells. Similar results were obtained in the multiple regression analysis carried out in the whole group of obese women. Thus, the results obtained in this study may, in some extent, reflect the relationship between the severity of endothelial dysfunction, glycemic status and insulin resistance degree. Similar observations were performed by Song et al. [43]. It was pointed in other research that an increase in sICAM-1 and E-selectin levels is most pronounced in patients with T2DM [44]. Also Mizia-Stec et al. [45] noted higher levels of E-selectin in patients with stable coronary artery disease and type 2 diabetes. Furthermore, in a nested case-control substudy within the prospective Nurses' Health Study revealed that high concentrations of E-selectin and sICAM-1 are the independent predictors for development of T2DM in non-diabetic women [46]. More importantly, the levels of E-selectin in the prospective studies proved to be a stronger predictor of T2DM than SICAM-1 and sVCAM-1 [47]. Additionally, an increase in serum levels of E-selectin allows to predict cardiovascular events in patients with type 2 diabetes [48]. In turn, the reverse correlation between the concentrations of sICAM-1, E-selectin and HDL-cholesterol demonstrated in T2DM group should be mainly associated with protective effect of HDL-cholesterol on the endothelial function confirmed in numerous in vitro and in vivo studies [49,50]. Another observed association in the T2DM subgroup was a positive correlation between the triglycerides and sVCAM-1 levels. It is consistent with recent research by Wang et al. [51], which showed that circulating triglyceride-rich lipoproteins and endoplasmic reticulum stress modulate the expression of adhesion molecules, in particular VCAM-1, which plays an important role in the development of endothelial inflammation. Gustavson et al. [52] pointed out that high levels of glucose and cholesterol are an 
important factor stimulating the expression of VCAM-1 in retinal vessels in ApoE-/-mice. In turn, Ghoneim et al. [53] demonstrated that an increase in sICAM and sVCAM concentrations is closely related to the development of neuropathy, nephropathy or retinopathy in patients with DM. Metabolic disturbances in diabetes play an important role in the development of endothelial dysfunction and contribute to the creation of complications such as micro-and macroangiopathy [54]. The relationship between VCAM-1 expression in the endothelium of carotid artery and atherosclerosis plaque progression and the occurrence of coronary artery disease (CAD) was demonstrated in animal model studies [55].

The crucial role in atherosclerotic processes development is played by CCL2. As prospective studies indicate, an increase in the concentrations of this chemokine is closely associated with an higher risk of the incidence of cardiovascular disease, in particular in the obese patients [56]. In the examined groups of obese women, its concentrations reached similar values and were almost twice higher compared to the control group. Just as in studies presented by other authors [57], they correlated significantly with BMI values. This relationship is, inter alia, the consequence of an increased expression of CCL2 in obese patients, primarily in omental fat. The increase in that protein concentration also reflects an increased migration of monocytes to endothelium, and thus the severity of inflammatory and atherogenic processes in the examined groups of obese patients. Blocking of CCL2 or its receptor reduces insulin resistance and hepatic steatosis in the experiments in animal models [58]. In our study, like Herder et al. [59], we demonstrated no relationship between CCL2 concentrations and the degree of glucose metabolism disturbance in groups of obese patients.

In the present study, significantly higher CRP concentrations were noted in all examined subgroups of obese women compared to the control group. They were significantly correlated with the indices defining the obesity degree. The similar results were obtained by multivariate stepwise regression analysis performed for the whole group of obese women. BMI was the best independent predictor of CRP levels. Our observations confirm the particular importance of obesity in the induction of low-grade systemic inflammation and are well comparable with the results of other works $[57,60]$. As mentioned previously, the available data indicate that CRP is not only a marker of inflammation, but more importantly it is directly involved in inflammatory and atherogenic processes ongoing in the vessel wall. It is also suggested by a significant correlation of CRP concentrations with levels of E-selectin, molecule closely related to atherogenesis, noted in T2DM subgroup. Our observations are consistent with in vitro studies carried out by Pasceri et al. [29], who point the direct involvement of CRP in the induction of adhesion molecules expression in human coronary artery endothelial cells. The study conducted by Barbalho et al. [61] in the group of patients undergoing arteriography showed higher levels of lipids and CRP in patients with hyperglycemia compared to normoglycemic ones. It is believed that the accumulation of this protein in the subendothelial space depends both on its systemic concentration and local synthesis. Endothelial and smooth muscle cells stimulated by proinflammatory cytokines, as well as monocytes/macrophages are its considerable source [62].

C-peptide occupies a special position among the factors affecting the development of the atherogenic process. While its deficiency in type 1 diabetes predisposes to microvascular complications, its increase in patients with insulin resistance and in the early stages of type 2 diabetes results in deposition of this peptide in the intima of vessels. These deposits, appearing in the early atheromatous changes, are accompanied by infiltration of inflammatory cells and an increased proliferation of smooth muscle cells. Luppi et al. [63] pointed an attention to the anti-inflammatory effect of physiological concentrations of C-peptide related to decreased release of IL-8 and CCL2, reduced expression of sVCAM-1 and suppression of NF-kappa B activation in endothelial cells exposed to hyperglycemia. On the other hand, higher concentrations of C-peptide in patients with T2DM enhanced the chemotactic activity of the monocytes/macrophages, the expression of the scavenger receptor CD34 on THP-1 monocytes and facilitated their transformation into foam cells [40]. Moreover, recent studies by Kim et al. [64] demonstrated the a relationship between C-peptide concentrations and intima media thickness in patients with T2DM. Pro-atherogenic effect of C-peptide is also suggested in the results of obtained our study. In patients with T2DM, its serum levels positively correlated with the concentration of CLL2, E-selectin, which is consistent with the observations by Marx et al. [65]. In early atheromatous lesions in diabetic subject vessels wall they showed an intimal colocalization of C-peptide deposits and monocytes/macrophages. They also observed that C-peptide levels are associated with cardiovascular mortality in patients undergoing coronary angiography, even after adjustment for markers of glucose metabolism [66]. Moreover, the multivariate stepwise regression analysis indicated that low 
HDL-cholesterol concentrations are the independent predictor of higher fasting C-peptide levels in the whole group of obese patients. However, the mechanism underlying this association is complex and not yet fully understood [67]. The results of our study, namely the inverse association between fasting C-peptide concentrations with IL-10 and positive with E-selectin and triglycerides levels, and support the hypothesis that C-peptide may be the active player in diabetic atherogenesis.

The protective effect of Th2 IL-10 both in the early stages of atherosclerotic plaque formation and its stabilization has been documented on various animals models. In studies conducted on IL-10-deficient mice an increased tendency to diet-induced atherosclerosis was observed [68]. Significant mechanisms through which this interleukin reduces the atherogenic process include inhibition of proinflammatory cytokines secretion by activated monocytes. In addition, IL-10 facilitates an uptake of modified LDL by macrophages, as well as transport of cholesterol excess from tissue macrophages [19]. The levels of IL-10 in the examined T2DM and IFG subgroups of obese women were significantly higher than the values obtained in the control group. The contribution of IL-10 in modulation of inflammatory response in endothelium cells suggests reverse association between this anti-inflammatory cytokine and CLL2 and E-selectin levels in T2DM subgroup. However, in contrast to other authors [69] we have not observed a decline of its concentrations in T2DM patients. It is possible that protective increase in IL-10 levels characterizes only obese patients without significant carbohydrate metabolism disorders, prediabetes and early stages of T2DM. Instead, its concentration decrease in more advanced stage of T2DM is a factor favoring the development of vascular complications. In this context, an interesting observation was made by Lee et al. [70]. The authors demonstrated that higher concentration of this interleukin is related to a lower risk of diabetic retinopathy in T2DM patients. It should be added that IL-10 affects endothelial function by stimulation of various signaling pathways. The proposed mechanisms of anti-inflammatory IL-10 activity involve an inhibiting of the activation of inflammatory cytokines genes transcription by the transcription factor NF- $\kappa \mathrm{B}$, induction of suppressor of cytokine synthesis-3, stimulation of Th2 cytokines and protection against Ang II-induced vascular dysfunction [71]. Furthermore, the important relationship noted in the group of T2DM patients and suggesting the participation of IL-10 in the regulation of glucose metabolism, is its negative correlation with
HOMA-IR. This findings is consistent with the results of the study conducted on transgenic mice showing that overexpression of IL-10 was a factor which prevented diet-induced muscle insulin resistance [72].

In summary, analyzed clinical and biochemical parameters in groups of patients with impaired glucose metabolism were significantly higher than in the control group. Significantly higher serum concentrations of adhesion molecules, CCL2 and CRP were noted in the examined groups of obese patients compared to the control group. Immunological activation to the greatest extent related to obese patients with type 2 diabetes. Concentration of adhesion molecules in these patients were significantly higher than those obtained in other groups of obese patients, and strictly positively correlated with the concentrations of glucose (ICAM-1), HOMA-IR values (E-selectin), and negatively with the concentrations of HDLC (s ICAM-1, E-selectin) and triglycerides (sVCAM-1).

An important role of adipose tissue in inflammatory processes induction in endothelium is emphasized by the correlation of CCL2 and CRP concentrations with parameters characterizing the degree of obesity obtained in the groups of obese patients. It should be noted, that their concentrations achieve similar values in all groups of obese patients, and are significantly higher than those obtained in the control group. Strictly positive relationship between concentrations of C-peptide and CCL2 and E-selectin, and negative with IL-10 concentrations, were noted in T2DM group. The concentrations of IL-10 in groups with impaired glucose metabolism were significantly higher than the values obtained in NGF and control groups. They demonstrated a strict negative correlation with the concentrations of CCL2, E-selectin, C-peptide and HOMA-IR values.

In conclusion, disturbed lipid and carbohydrate metabolism are manifested by enhanced inflammation and endothelial dysfunction in patients with simply obesity. These disturbances are associates with an increase of adhesion molecules. The results suggest the probable active participation of higher concentrations of C-peptide in the intensification of inflammatory and atherogenic processes in in obese patients with type 2 diabetes. In patients with obesity and type 2 diabetes, altered serum concentrations of Il-10 seems to be dependent on the degree of insulin resistance and proinflammatory status. However, larger studies are necessary to confirm these results.

The main limitation of our study is the lack of more accurate methods of insulin resistance assessment such as hyperinsulinemic-euglycemic clamp technique, and functional tests of endothelial dysfunction like flow mediated dilation (FMD). 
Furthermore some analyses have limited statistical power due to a relatively small number of subjects.

\section{Abbreviations}

ADA: American Diabetes Association; BMI: Body Mass Index; BP: blood pressure; CCL2: chemokine (C-C motif) ligand 2; T2DM: type 2 Diabetes Mellitus; FMD: flow mediated dilation; HDLC: high-density lipoprotein cholesterol; HOMA-IR: Homeostasis Model Assessment of Insulin Resistance Index; CRP: C-reactive protein; IFG: Impaired Fasting Glucose; IL-10: interleukin-10; iNOS: inducible nitric oxide synthase; LDL: low-density lipoprotein cholesterol; NFG: Normal Fasting Glucose; sICAM-1: soluble intercellular adhesion molecules 1; sVCAM-1: soluble vascular cell adhesion molecule 1.

\section{Acknowledgments}

We are grateful to Medical University of Silesia for providing the research funding.

\section{Competing Interests}

The authors have declared that no competing interest exists.

\section{References}

1. van Sloten TT, Henry RM, Dekker JM, et al. Endothelial dysfunction plays a key role in increasing cardiovascular risk in type 2 diabetes: the Hoorn study. Hypertension. 2014;64:1299-1305.

2. Ding H, Triggle CR. Endothelial cell dysfunction and the vascular complications associated with type 2 diabetes: assessing the health of the endothelium. Vasc Health Risk Manag. 2005; 1: 55-71.

3. Bakker W, Eringa EC, Sipkema P, van Hinsbergh VW. Endothelial dysfunction and diabetes: roles of hyperglycemia, impaired insulin signaling and obesity. Cell Tissue Res. 2009; 335: 165-189.

4. Mah E, Noh SK, Ballard KD, et al. Postprandial hyperglycemia impairs vascular endothelial function in healthy men by inducing lipid peroxidation and increasing asymmetric dimethylarginine:arginine1-3. J Nutr. 2011; 141: 1961-1968.

5. Kumar P, Rao GN, Pal BB, Pal A. Hyperglycemia-induced oxidative stress induces apoptosis by inhibiting PI3-kinase/Akt and ERK1/2 MAPK mediated signaling pathway causing downregulation of 8-oxoG-DNA glycosylase levels in glial cells. Int J Biochem Cell Biol. 2014; 53: 302-319.

6. Peng J, Li X, Zhang D, et al. Hyperglycemia, p53, and mitochondrial pathway of apoptosis are involved in the susceptibility of diabetic models to ischemic acute kidney injury. Kidney Int. 2015; 87: 137-150.

7. $\mathrm{Li} \mathrm{J}$, Wang $\mathrm{P}, \mathrm{Yu} \mathrm{S}$, Zheng $\mathrm{Z}$, Xu X. Calcium entry mediates hyperglycemia-induced apoptosis through $\mathrm{Ca}(2+)$ /calmodulin-dependent kinase II in retinal capillary endothelial cells. Mol Vis. 2012; 18: 2371-2379.

8. Smith-Palmer J, Brändle M, Trevisan R, et al. Assessment of the association between glycemic variability and diabetes related complications in type 1 and type 2 diabetes. Diabetes Res Clin Pract. 2014; 105: 273-284.

9. Huang ES, Laiteerapong N, Liu JY, et al. Rates of complications and mortality in older patients with diabetes mellitus: the diabetes and aging study. JAMA Intern. Med. 2014; 174: 251-258.

10. Fotis L, Agrogiannis G, Vlachos IS, et al. Intercellular adhesion molecule (ICAM)-1 and vascular cell adhesion molecule (VCAM)-1 at the early stages of atherosclerosis in a rat model. In Vivo. 2012; 26: 243-250.

11. Urso C, Hopps E, Caimi G. Adhesion molecules and diabetes mellitus. Clin Ter. 2010; 161: e17-24.

12. Elhadd TA, Kennedy G, Robb R, et al. Elevated soluble cell adhesion molecules, E-selectin and intercellular cell adhesion molecule-1 in type-2 diabetic patients with and without asymptomatic peripheral arterial disease. Int Angiol. 2004; 23:128-133.

13. Arner E, Mejhert N, Kulyté A, et al. Adipose tissue microRNAs as regulators of CCL2 production in human obesity. Diabetes. 2012; 61: 1986-1993.

14. Panee J. Monocyte chemoattractant protein 1 (MCP-1) in obesity and diabetes. Cytokine. 2012; 60: 1-12.
15. Zhang X, Liu X, Shang H, Xu Y, Qian M. Monocyte chemoattractant protein-1 induces endothelial cell apoptosis in vitro through a p53-dependent mitochondrial pathway. Acta Biochim Biophys Sin. 2011; 43: 787-795.

16. Hong $\mathrm{KH}, \mathrm{Ryu} \mathrm{J}$, Han $\mathrm{KH}$ : Monocyte chemoattractant protein 1-induced angiogenesis is mediated by vascular endothelial growth factor-A. Blood. 2005; 105:1405-1407.

17. Tateya S, Tamori $\mathrm{Y}$, Kawaguchi $\mathrm{T}$, et al. An increase in the circulating concentration of monocyte chemoattractant protein-1 elicits systemic insulin resistance irrespective of adipose tissue inflammation in mice. Endocrinology. 2010; 151: 971-979.

18. Halvorsen $\mathrm{B}$, Wæhre $\mathrm{T}$, Scholz $\mathrm{H}$, et al. Interleukin-10 enhances the oxidized LDL-induced foam cell formation of macrophages by antiapoptotic mechanisms. J Lipid Res. 2005; 46: 211-219.

19. Han, $X$, Kitamoto $S$, Wang $H$, Boisvert WA. Interleukin-10 overexpression in macrophages suppresses atherosclerosis in hyperlipidemic mice. FASEB J. 2010; 24: 2869-2880.

20. Waehre T, Halvorsen B, Damås JK, et al. Inflammatory imbalance between IL-10 and TNF alpha in unstable angina potential plaque stabilizing effects of IL-10. Eur J Clin Invest. 2002; 32: 803-810.

21. Kamimura M, Viedt C, Dalpke A, et al. Interleukin-10 suppresses tissue factor expression in lipopolysaccharide-stimulated macrophages via inhibition of Egr-1 and a serum response element/MEK-ERK1/2 pathway. Circ Res. 2005; 97: 305-313.

22. Yang $\mathrm{H}$, Chen SC. The effect of interleukin- 10 on apoptosis in macrophages stimulated by oxLDL. Eur J Pharmacol. 2011; 657: 126-130.

23. Dhingra S, Bagchi AK, Ludke AL, Sharma AK, Singal PK. Akt regulates IL-10 mediated suppression of TNFa-induced cardiomyocyte apoptosis by upregulating Stat3 phosphorylation. PLoS One. 2011; 6: e25009

24. Little PJ, Chait A, Bobik A. Cellular and cytokine-based inflammatory processes as novel therapeutic targets for the prevention and treatment of atherosclerosis. Pharmacol Ther. 2011; 131: 255-268.

25. Heeschen C, Dimmeler S, Hamm CW, et al. Serum level of the antiinflammatory cytokine interleukin-10 is an important prognostic determinant in patients with acute coronary syndromes. Circulation. 2003;107: 2109-2114

26. Tziakas DN, Chalikias GK, Kaski JC, et al. Inflammatory and anti-inflammatory variable clusters and risk prediction in acute coronary syndrome patients: a factor analysis approach. Atherosclerosis. 2007;193:196-203.

27. Kaplan M, Hamoud S, Tendler Y, et al. A significant correlation between C-reactive protein levels in blood monocytes derived macrophages versus content in carotid atherosclerotic lesions. J Inflamm (Lond). 2014; 11:7.

28. Torzewski J, Torzewski M, Bowyer DE, et al. C-reactive protein frequently colocalizes with the terminal complement complex in the intima of early atherosclerotic lesions of human coronary arteries. Arterioscler Thromb Vasc Biol. 1998; 18: 1386-1392.

29. Pasceri V, Willerson JT, Yeh ETH. Direct proinflammatory effect of C-reactive protein on human endothelial cells. Circulation. 2000; 102: 2165-2168.

30. Haltori Y, Matsumura M, Kasai K. Vascular smooth muscle cell activation by C-reactive protein. Cardiovasc Res. 2003; 58:186-195

31. Devaki RN, Gowdappa H. Basavana, Suma MN, et al. A study of C-reactive protein and its relationship with CHD and lipid metabolism. Int J Pharm Sci Rev Res. 2011; 6: 125-127.

32. Yeo ES, Hwang JY, Park JE, et al. Tumor necrosis factor (TNF-alpha) and C-reactive protein (CRP) are positively associated with the risk of chronic kidney disease in patients with type 2 diabetes. Yonsei Med J. 2010; 5: 519-525.

33. Zhong Z, Kotova O, Davidescu A, et al. C-peptide stimulates Na+, K+-ATPase via activation of ERK1/2 MAP kinases in human renal tubular cells. Cell Mol Life Sci. 2004; 61: 2782-2790.

34. Walcher D, Babiak C, Poletek P, et al. C-peptide induces vascular smooth muscle cell proliferation: involvement of Src kinase, phosphatidylinositol 3-kinase, and extracellular signal regulated kinase 1/2. Circ Res. 2006; 99: 1181-1187.

35. Lim YC, Bhatt MP, Kwon MH, et al. Proinsulin C-peptide prevents impaired wound healing by activating angiogenesis in diabetes. J Invest Dermatol. 2015; 135: 269-278.

36. Joshua IG, Zhang Q, Falcone JC, et al. Mechanisms of endothelial dysfunction with development of type 1 diabetes mellitus: role of insulin and C-peptide. J Cell Biochem. 2005; 96: 1149-1156.

37. Lim YC, Bhatt MP, Kwon MH, et al. Prevention of VEGF-mediated microvascular permeability by C-peptide in diabetic mice. Cardiovasc Res. 2013; 101: 155-164

38. Bhatt MP, Lim YC, Hwang J, et al. C-peptide prevents hyperglycemia induced endothelial apoptosis through inhibition of reactive oxygen species-mediated transglutaminase 2 activation. Diabetes. 2013; 62: 243-253.

39. Bhatt MP, Lim YC, Kim YM, et al. C-peptide activates AMPK alpha and prevents ROS-mediated mitochondrial fission and endothelial apoptosis in diabetes. Diabetes. 2013; 62: 3851-3862.

40. Mavrakanas T, Frachebois A, Aloui SF, et al. C-peptide and chronic complications in patients with type- 2 diabetes and the metabolic syndrome. Presse Med. 2009; 38: 1399- 1403.

41. [No authors listed]. American Diabetes Association. Diagnosis and classification of diabetes mellitus. Diabetes Care. 2012; 35(Suppl 1): S64-S71. 
42. Ziccardi P, Nappo F, Giugliano G, et al. Reduction of inflammatory cytokine concentrations and improvement of endothelial functions in obese women after weight loss over one year. Circulation. 2002; 105: 804-809.

43. Song Y, Manson JE, Tinker L, et al. Circulating levels of endothelial adhesion molecules and risk of diabetes in an ethnically diverse cohort of women. Diabetes. 2007; 56: 1898-1904.

44. Elhadd TA, Kennedy G, Robb $R$, et al. Elevated soluble cell adhesion molecules E-selectin and intercellular cell adhesion molecule-1 in type-2 diabetic patients with and without asymptomatic peripheral arterial disease. Int Angiol. 2004; 23: 128-133.

45. Mizia-Stec K, Gąsior Z, Zahorska-Markiewicz B, et al. Aktywacja immunologiczna w cukrzycy typu 2 u osób z chorobą wieńcową. Diabetol Dośw Klin. 2003; 3: 523-529.

46. Meigs JB, Hu FB, Rifai N, Manson JE. Biomarkers of endothelial dysfunction and risk of type 2 diabetes mellitus. JAMA. 2004; 291: 1978-1986.

47. Cui W, Song Y. Potential clinical usefulness of endothelial adhesion molecules in predicting risk of type 2 diabetes. N A J Med Sci. 2009; 2: 60-63.

48. Matsumoto K, Fujishima K, Moriuchi A, Saishoji H, Ueki Y. Soluble adhesion molecule E-selectin predicts cardiovascular events in Japanese patients with type 2 diabetes mellitus. Metabolism. 2010; 59: 320-324.

49. Riwanto M, Rohrer L, Roschitzki B, et al. Altered activation of endothelial antiand proapoptotic pathways by high-density lipoprotein from patients with coronary artery disease: role of high-density lipoprotein-proteome remodeling. Circulation. 2013; 127: 891-904.

50. Besler C, Luscher TF, Landmesser U. Molecular mechanisms of vascular effects of high-density lipoprotein: alterations in cardiovascular disease. EMBO Mol Med. 2012; 4: 251-268.

51. Wang YI, Bettaieb A, Sun C, et al. Triglyceride-rich lipoprotein modulates endothelial vascular cell adhesion molecule (VCAM)-1 expression via differential regulation of endoplasmic reticulum stress. PLoS One. 2013; 8: e78322.

52. Gustavsson C, Agardh CD, Zetterqvist AV, Nilsson J, Agardh E, Gomez MF. Vascular cellular adhesion molecule-1 (VCAM-1) expression in mice retinal vessels is affected by both hyperglycemia and hyperlipidemia. PLOS One. 2010;13; e12699.

53. Ghonaim MM, El-EdeL R. Circulating cell adhesion molecules (sICAM-1 and sVCAM-1) and microangiopathy in diabetes mellitus. Ibnosina J Med BS. 2015; 7: 211-218

54. Nwose EU, Richards RS, Bwititi PT. Cardiovascular risks in prediabetes: preliminary data on "vasculopathy triad". N. Am. J. Med. Sci. 2014; 6: 328-332.

55. Masseau I,bBowles DK. Carotid endothelial VCAM-1 Is an early marker of carotid atherosclerosis and predicts coronary artery disease in swine. J Biomed Sci Eng. 2015; 8: 767-779.

56. Kim CS, Park HS, Kawada Tet al. Circulating levels of MCP-1 and IL-8 are elevated in human obese subjects and associated with obesity-related parameters. Int J Obes (Lond). 2006; 30: 1347-1355.

57. Nishitani N, Sakakibara H. Association between body mass index and high-sensitivity C-reactive protein in male Japanese. Obes Res Clin Pract. 2013; 7: e295-e300.

58. Tamura $\mathrm{Y}$, Sugimoto M, Murayama T, et al. Inhibition of CCR2 ameliorates insulin resistance and hepatic steatosis indb/dbmice. Arterioscler Thromb Vasc Biol. 2008; 28: 2195-2201.

59. Herder C, Muller-Scholze S, Rating R, et al. Systemic monocyte chemoattractant protein-1 concentrations are independent of type 2 diabetes or parameters of obesity: results from the Cooperative Health Research in the Region of Augsburg Survey S4 (KORA S4). Eur J Endocrinol. 2006; 154: 311-317.

60. Timpson NJ, Nordestgaard BG, Harbord RM, et al. C-reactive protein levels and body mass index: elucidating direction of causation through reciprocal Mendelian randomization. Int J Obes (Lond). 2011; 35: 300-308.

61. Barbalho SM, Toffano RJ, Bechara MD, et al. Association between hyperglycemia, C-reactive protein and other risk factors in patients at cardiovascular risk. Journal of Diabetes Mellitus. 2016; 6: 16-24.

62. Behl T, Goel H, Kaur I, et al. Role of C-reactive protein in diabetes mellitus and its associated complications. IAJPR. 2014; 4: 5315-5320.

63. Luppi $\mathrm{P}$, Cifarelli V, Tse $\mathrm{H}$, et al. Human C-peptide antagonises high glucose-induced endothelial dysfunction through the nuclear factor- $\mathrm{kB}$ pathway. Diabetologia. 2008; 51: 1534-1543.

64. Kim ST, Kim BJ, Lim DM, et al. Basal C-peptide level as a surrogate marker of subclinical atherosclerosis in type 2 diabetic patients. Diabetes Metab J. 2011; 35: 41-49.

65. Marx N, Walcher D, Raichle C, et al. C-peptide colocalizes with macrophages in early arteriosclerotic lesions of diabetic subjects and induces monocyte chemotaxis in vitro. Arterioscler Thromb Vasc Biol. 2004; 24: 540-545.

66. Marx N, Silbernagel G, Brandenburg V, et al. Diabetes C-Peptide levels are associated with mortality and cardiovascular mortality in patients undergoing angiography. The LURIC study. Diabetes Care. 2013; 36: 708-714.

67. $\mathrm{Li}$ Y, Li Y, Meng L, Zheng L. Association between serum C-peptide as a risk factor for cardiovascular disease and high-density lipoprotein cholesterol levels in nondiabetic individuals. PLoS ONE 2015; 10: e112281.

68. Mallat $\mathrm{Z}$, Besnard S, Duriez $\mathrm{M}$, et al. Protective role of interleukin-10 in atherosclerosis. Circ Res. 1999; 85: e17-e24.

69. van Exel E, Gussekloo J, de Craen AJ, et al. Low production capacity of interleukin-10 associates with the metabolic syndrome and type 2 diabetes: the Leiden 85-Plus Study. Diabetes. 2002; 51: 1088-1092.
70. Lee JH, Lee $\mathrm{W}$, Kwon $\mathrm{OH}$, et al. Cytokine profile of peripheral blood in type 2 diabetes mellitus patients with diabetic retinopathy. Ann Clin Lab Sci. 2008; 38: 361-367.

71. Didion SP, Kinzenbaw DA, Schrader LI, et al. Endogenous interleukin-10 inhibits angiotensin II-induced vascular dysfunction. Hypertension 2009; 54: 619-624.

72. Hong EG, Ko HJ, Cho YR, et al. Interleukin-10 prevents diet-induced insulin resistance by attenuating macrophage and cytokine response in skeletal muscle. Diabetes 2009; 58: 2525-2535. 